ORIGINAL PROF-2080

\title{
BRAIN ABSCESS;
}

Children in Southern province of Saudi Arabia Kingdom.

Dr. Mubarak Aloraij

ABSTRACT... Objective: To evaluate the clinical presentation, diagnosis, sources of infection, surgical management outcome and microorganisms involved in the brain abscess in our locality. Period \& Setting: This study was carried out in the department of Neurosurgery, Aseer Central Hospital Abha, Southern Province, KSA from 1426 H - 1433 H (2005-2012 AD). Material and Methods: A total of 30 children aged less than 15 years were reviewed. There were 15 males and 15 females. The mean age of presentation was $5.6 \pm 4.4$ years. Results: Typically patients presented with fever, vomiting, headache and seizures. The predisposing conditions found were cyanotic congenital heart disease in 11 (37\%) of children, meningitis in 6 (20\%), septicemia in 7 (23\%) and no underlying cause was found in $5(17 \%)$ children. The most common microbe in children with cyanotic congenital heart disease was of the Streptococcus milleri group (52\%). All abscesses were large, more than $2 \mathrm{~cm}$ in diameter and were aspirated surgically. Excision was performed in 6 children. Five children expired, one due to a intracranial bleeding and the others due to severe cerebral edema and tentorial hemiation. Complications were seen in 20 children and 16 had sequelae, hemiparesis in 11 and seizure disorder in 5 . Conclusions: It is concluded from the study that delayed surgical drainage has high morbidity and mortality. Diagnosis with CT scan, appropriate antibiotic therapy and complete aspiration of abscess reduced the mortality and neurological deficits from brain abscess.

Key words:Brain abscess, cyanotic congenital heart disease.

Article Citation

$\checkmark \quad$ Aloraij M. Brain abscess in children in Southern province of Saudi Arabia Kingdom. Professional Med J Feb 2013;20(1): 030-033.

\section{INTRODUCTION}

Brain abscess is a serious life threatening infection of brain parenchyma'. It results from spread of infection from contiguous non-neuronal tissue, hematogenous seeding or a direct introduction into the brain $^{2,3}$. Predisposing factors identified include congenital heart disease with a right to left shunt, infections of the middle ear, mastoid, paranasal sinuses, orbit, face, scalp, penetrating skull injury, comminuted skull fracture or intracranial surgery including insertion of ventriculo-peritoneal shunts, dermal sinuses and abnormal immune functions $\mathrm{s}^{2,3,4,5,6}$.

The objective of this study was to look at the clinical profile, microbiology and outcome of children with cerebral abscess having an underlying congenital heart disease as compared to other predisposing conditions.

\section{MATERIAL AND METHODS}

Thirty consecutive children admitted over the last ten years with the diagnosis of brain abscess were reviewed retrospectively. The clinical presentation, predisposing factors, diagnosis, management and outcome were noted. There were 15 males and 15 females. The mean age at presentation was $5.6 \pm 4.4$ years (range 1 month -14 years).

\section{RESULTS}

The mean duration of illness at the time of presentation was $17.6 \pm 24.6$ days (range 1 day to 120 days). All children, except one neonate, presented with fever. Other symptoms at presentation included vomiting $(60 \%)$, headache (45\%) and seizures (45\%) (Table-I).

Eleven children (37\%) had a cyanotic congenital heart disease of which 5 (45\%) had tetralogy of Fallot and its variants, $3(27 \%)$ had transposition of great arteries and $3(27 \%)$ had tricuspid atresia. One patient with tetralogy of Fallot had coexisting Factor IX deficiency and one with tricuspid atresia had infective endocarditis. Previous palliative operation in the form 


\begin{tabular}{|l|c|c|}
\hline \multicolumn{1}{|c|}{ Disease } & No. of cases & \%age \\
\hline Congenital heart disease & 11 & 37.0 \\
\hline Previous operations:- & & \\
- Blalock Taussig shunt & 08 & 26.0 \\
- Ventriculo-peritoneal shunt & 01 & 03.0 \\
\hline Septicemia & 07 & 23.0 \\
\hline Meningitis & 06 & 20.0 \\
\hline
\end{tabular}

Table-I. Predisposing factors in children with brain abscess

of Blalock Taussig shunt was done in 8 patients. Polycythemia was present in $9(88 \%)$ patients in whom the mean hemoglobin and hematocrit were $18.2( \pm 3.4) \mathrm{gm} / \mathrm{dl}$ and $54( \pm 9) \%$ respectively (Table II).

\begin{tabular}{|l|c|c|}
\hline \multicolumn{1}{|c|}{ Diagnosis } & No. of cases & \%age \\
\hline Tetralogy of Fallot & 04 & 13.3 \\
\hline Tricuspid atresia & 03 & 10.0 \\
\hline d- TGA, VSD, PS & 02 & 06.7 \\
\hline Pulmonary atresia, VSD & 01 & 03.0 \\
\hline d- TGA, single ventricle & 01 & 03.0 \\
\hline \multicolumn{2}{|c|}{ VSD, ventricular septal defect, } \\
TGA transposition of great arteries, \\
PS- pulmonary stenosis \\
\hline \multicolumn{2}{|c|}{ Table-II. Type of predisposing cyanotic } \\
\hline
\end{tabular}

Midline shift and cerebral edema was noted in 19 and 17 children each. Abscess was drained by burr hole in all. Repeated drainage and excision were done in 14 and 6 patients respectively. Management included mannitol in 18 (60\%), antibiotics (ceftrioxone in 92\%, cloxacillin, metronidazole, benzyl penicillin in others) were given according to sensitivities, initial therapy for anaerobes with metronidazole in all and anticonvulsants in 5 patients. Duration of antibiotic therapy ranged from 14 to 40 days. Duration of hospitalization was more in children with congenital heart disease (Table-III).

\begin{tabular}{|l|c|c|c|}
\hline \multicolumn{1}{|c|}{ Factors } & $\begin{array}{c}\text { Congenital } \\
\text { heart disease } \\
\mathbf{( n = 1 1 )}\end{array}$ & $\begin{array}{c}\text { 0ther } \\
\text { diseases } \\
\mathbf{( n = 1 9 )}\end{array}$ & $\begin{array}{c}\text { P- } \\
\text { value }\end{array}$ \\
\hline Age (years) & $7.5 \pm 3.4$ & $\begin{array}{c}4.46 \pm \\
4.6\end{array}$ & 0.04 \\
\hline $\begin{array}{l}\text { Duration of } \\
\text { illness }\end{array}$ & $25.5 \pm 35.4$ & $\begin{array}{c}12.6 \pm \\
13.1\end{array}$ & 0.04 \\
\hline $\begin{array}{l}\text { Glasgow Coma } \\
\text { Scale }\end{array}$ & $13.5 \pm 3.0$ & $\begin{array}{c}13.8 \pm \\
3.2\end{array}$ & 0.98 \\
\hline WBC count & $16.0 \pm 4.4$ & $\begin{array}{c}16.7 \pm \\
9.9\end{array}$ & 0.10 \\
\hline ESR & $22.8 \pm 24.8$ & $\begin{array}{c}32.6 \pm \\
21.5\end{array}$ & 0.92 \\
\hline Serum Sodium & $136 \pm 3$ & $135 \pm 9$ & 0.7 \\
\hline Midline shift & $8 / 11$ & $10 / 19$ & 0.045 \\
\hline Cerebral edema & $9 / 11$ & $8 / 19$ & 0.03 \\
\hline Sequelae & $7 / 11$ & $9 / 19$ & 0.05 \\
\hline $\begin{array}{l}\text { Duration of } \\
\text { hospitalization }\end{array}$ & $18.6 \pm 13.8$ & $\begin{array}{c}14.2 \pm \\
9.6\end{array}$ & 0.57 \\
\hline Death & $4 / 11$ & $1 / 19$ & 0.02 \\
\hline Table-III. Differences in children with congenital heart \\
disease and other predisposing factors
\end{tabular}

\section{DISCUSSION}

Cerebral abscess is a serious infection of the brain parenchyma. Several predisposing factors are causally related, but in $14-25 \%$ of patients no cause can be found ${ }^{7}$. In our series 5 (17\%) children did not have an identifiable associated disease. In one study, otogenic source was the commonest predisposing factor, found in $34 \%$ of patients ${ }^{5}$. However, proper treatment of infections of middle ear, mastoid, scalp and face has reduced the incidence of this source ${ }^{2}$.

In our study, no patient had these infections as a preceding event. Un-operated cyanotic congenital 
heart disease (CCHD) is an important predisposing factor for brain abscess, accounting for $25-46 \%$ of cases $^{6,7,8}$.

In our study 11 (37\%) had CCHD. The risk of brain abscess complicating CCHD is inconstant but is more common after 2 yrs of age and increases continuously until the age of 12 years. Instantaneous risk at that time is quoted as $1.75 \pm 0.12 \%$, but decreases thereafter ${ }^{3}$.

Risk factors predisposing to the development of brain abscess in CCHD include hypoxia and its consequent polycythemia and hyperviscosity. The latter results in sluggish blood flow in cerebral microcirculation that allows microthrombi formation and focal encephalomalacia. It also alters blood brain barrier permeability ${ }^{3}$.

In our study, the mean hematocrit in this group of children was $54 \pm 9 \%$. Shunted blood from the right side escapes the bacterial phagocytosis in the lungs and contains infectious organisms that seed these sites causing focal cerebritis. One study demonstrated reduced bactericidal and phagocytic functions of leucocytes in children with $\mathrm{CCHD}^{4}$. Although it could occur in any CCHD, the commonest CCHD associated is tetralogy of Fallot ${ }^{9}$.

In our series $45 \%$ of children had tetralogy of Fallot. Meningitis was seen in $6(20 \%)$ of children and septicemia in $7(23 \%)$. Microbial isolates in this series were interesting. Streptococcus milleri was the most common microbe isolated from pus in children with CCHD. Studies from Malaysia also found streptococcus milleri as the most common organism in this cohort of patients ${ }^{10}$.

Another regional study from Sri Lanka showed this microbe to be the most frequent pathogen, found in $35 \%$ cases of cerebral abscess, unrelated to underlying disease ${ }^{11}$. Streptococcus milleri group of organisms, comprising of $\mathrm{S}$. constellatus, $\mathrm{S}$. intermedius, S. anginosus, are a newly recognized cause of pyogenic infections. They are often associated with localized lesions and

abscess formation in various organs like brain, lungs and hepatobiliary system ${ }^{12,13}$.

Abscesses were all single located except in one case where multiple abscesses were seen and the patient who had infective endocarditis. Most common location was in the parietal region (in 55\%) in our cases. In other series, multiple abscesses were more common in immunocompromised children and infective endocarditis ${ }^{2,14}$.

Treatment is with systemic antibiotics and abscesses which are larger than $2 \mathrm{~cm}$ in diameter have to be drained surgically. Medical therapy is usually initiated before results of bacteriology are obtained with a properly selected drug that has good intracranial penetration. The combination of ampicillin and chloramphenicol has been proposed as the treatment of first intention. Adaptation of antimicrobial therapy then depends upon clinical, biological and bacteriological outcomes and results of cerebral imaging $^{15}$. The surgical options include burr hole and aspiration and in cases with recurrent reaccumulation, excision is required.

In our series, children with congenital heart disease had a significantly older age of presentation, prolonged duration of illness at the time of admission, also had significant cerebral complications like midline shift and cerebral edema. They also had more sequelae and a significantly higher mortality as compared to the noncardiac group ( $p=0.05$ and $p=0.02$ respectively) Prognosis largely depends on early diagnosis and appropriate therapy.15 Delayed presentation was obvious in our series. Presence of coma, multiplicity of brain abscesses, severe cerebral edema and immunocompromised host are associated with bad prognosis. 


\section{CONCLUSION}

It is concluded from the study that delayed surgical drainage has high morbidity and mortality. Diagnosis with CT scan, appropriate antibiotic therapy and complete aspiration of abscess reduced the mortality and neurological deficits from brain abscess.

\section{Copyright@ 05 Nov, 2012.}

\section{REFERENCES}

1. Yogev R, Bar-Meir M. Management of brain abscesses in children. Pediatr Infect Dis J 2004; 23(2):157-9.

2. Goodkin HP, Harper MB, Pomeroy SL. Intracranial abscess in children: Historical trends at Children's hospital, Boston. Pediatrics 2004; 111(8):1765-70.

3. Glickstein JS, Chandra RK, Thompson JW. Intracranial complications of pediatric sinusitis. Otolaryngol Head Neck Surg 2006; 134(5):733-6.

4. Brook I. Microbiology and antimicrobial treatment of orbital and intracranial complications of sinusitis in children and their management. Int $\mathrm{J}$ Pediatr Otorhinolaryngol 2009;73(9):1183-6.

5. Malik S, Joshi SM, Kandoth PW, Vengsarkar US. Experience with brain abscesses. Indian Pediatr 1994; $31(6): 661-6$.

6. Takeshita M, Kagawa M, Yonetani H, Izawa M, Yato S, Nakanishi T, Monma K. Risk factors for brain abscess in patients with congenital cyanotic heart disease. Neurol Med Chir 1992; 32(9): 667-70.

7. Weghtman NC, Barnham MRD, Dove M. Streptococcus milleri group bacteremia in North Yorkshire, England
(1989-2000). Indian J Med Res 2004; 119 (Suppl):164-7.

8. Pandian JD, Monma NV, Cherian PJ, Radhakrishnan K. Brainstem abscess complication tetralogy of Fallot successfully treated with antibiotics alone. Neurol India 2003; 48(3): 272-5.

9. Puthucheary SD, Parasakthi N. The bacteriology of brain abscess: a local experience in Malaysia. Trans R Soc Trop Med Hyg 1990; 84(4): 689-92.

10. Sineviratne RS, Navasivayam P, Perera S, Wickremasinghe RS. Microbiology of brain abscess at a neurosurgical unit of the National Hospital of Sri Lanka. Ceylon Med J 2003; 48(1):14-6.

11. Woo PC. Streptococcus milleri”endocarditis caused by streptococcus anginosus. Diagn Microbiol Infect Dis 2004; 48 (2): 81-8.

12. Kanamori S, Kusano N, Shinzato T, Saito A. The role of capsule of streptococcus milleri group in its pathogenicity. J Infect Chemother 2004; 10(2):105-9.

13. Yanagihara C, Wada $Y$, Nishimura $Y$. Infectious endocarditis associated with subarachnoid hemorrhage, subdural hematoma and multiple brain abscesses. Intern Med 2003; 42(12):1244-7.

14. Goodkin HP, Harper MB, Pomeroy SL. Intracerebral abscess in children: historical trends at Children's Hospital Boston. Pediatrics 2004; 113(6):1765-70.

15. Livraghi S, Melancia JP, Antunes JL. The management of brain abscesses. Adv Tech Stand Neurosurg 2003; 28: $285-313$

\section{AUTHOR(S):}

1. DR. MUBARAK ALORAIJ

Assistant Professor Neurosurgery,

King Khalid University, Abha Aseer Province

Southern Region KSA.
CORRESPONDENCE ADDRESS:

Dr. Mubarak Aloraij

Assistant Professor Neurosurgery,

King Khalid University, Abha Aseer Province

Southern Region KSA

mubarak01@hotmail.com

Article received on: $28 / 06 / 2012$ Accepted for Publication: 30/10/2012 Received after proof reading: 10/12/2012 